\title{
Behavior of Biaxially Loaded Slab-Column Connections with Shear Studs
}

\author{
by Eric M. Matzke, Rémy D. Lequesne, Gustavo J. Parra-Montesinos, and Carol K. Shield
}

Results are presented from four non-prestressed concrete slabcolumn connection subassemblies tested under simulated gravity and earthquake-type loading. Each specimen consisted of a largescale first-story interior slab-column connection reinforced with headed shear studs, loaded to a gravity-shear ratio of $50 \%$, and subjected to biaxial lateral displacements. The slabs, which were nominally identical aside from the shear stud reinforcement design, had a flexural reinforcement ratio in the column strip, based on the effective depth, of $0.7 \%$. Shear stud reinforcement in the test specimens varied in terms of amount and spacing, both between and within stud peripheral lines.

All four specimens exhibited drift capacities significantly lower than shown by previous studies. Although the lateral strength of the specimens was governed by the flexural capacity of the slab, severe concrete degradation ultimately limited the drift capacity of the connections. Signs of punching-related damage were first observed during the cycle to $1.85 \%$ drift in each loading direction. Test results suggest that the minimum amount of shear reinforcement required in Section 21.13.6 of ACI 318-11 when neither a drift nor a combined shear-stress check is performed $\left(\mathrm{v}_{\mathrm{s}} \geq 3.5 \sqrt{ } \mathrm{f}_{\mathrm{c}}{ }^{\prime}\right.$, psi $\left[0.29 \sqrt{\left.\mathrm{f}_{\mathrm{c}}{ }^{\prime}, \mathrm{MPa}\right]}\right.$ ) is adequate for connections subjected to a gravity shear ratio of up to $50 \%$ and resultant drifts from biaxial displacements of up to $2.0 \%$ if studs are spaced at less than $2 \mathrm{~d}$ within the first two peripheral lines. For larger drift demands, a maximum stud spacing within the first three peripheral lines of $1.5 \mathrm{~d}$ is recommended.

Keywords: confinement; drift capacity; punching shear; seismic; shear study; two-way slab.

\section{INTRODUCTION}

Slab-column frame systems that consist of flat slabs directly supported by columns have long represented an attractive structural option for buildings. Besides being architecturally appealing, the uniform bottom surface of the slab simplifies formwork and allows for reduced story heights. The lack of beams, however, requires a direct transfer of load from the slab to the columns, which makes the connections susceptible to punching shear failures and leads to a system that is relatively flexible laterally.

In regions of high seismicity, slab-column frames are often used in combination with either structural walls or special moment-resisting frames, which provide the required lateral stiffness and strength. Although typically not considered part of the lateral-force-resisting system, slab-column frames must be capable of supporting gravity loads while undergoing earthquake-induced displacements.

In ACI 318-11 (ACI Committee 318 2011), it is assumed that slab-column frames that are not part of the seismic force-resisting system have adequate drift capacity if one of the following conditions is met:
1. For slabs without shear reinforcement, the design drift does not exceed the larger of 0.005 and [0.035$\left.0.05 v_{u g} /\left(\phi v_{c}\right)\right]$, where $v_{u g}$ is the shear stress due to gravity load, $\phi=0.75$, and $v_{c}$ is the nominal shear strength (in terms of stress) assigned to the concrete;

2. For slabs with shear reinforcement, a minimum amount of shear reinforcement is provided such that $v_{s} \geq 3.5 \sqrt{ } f_{c}{ }^{\prime}$, psi $\left(0.29 \sqrt{ } f_{c}{ }^{\prime}, \mathrm{MPa}\right)$ over at least four times the slab thickness from the column faces, where $v_{s}$ is the nominal shear strength (stress) assigned to the reinforcement; or

3. The shear-stress demand due to gravity shear and moment transferred in the connection at the design lateral displacement, calculated according to the eccentric shearstress model in Chapter 11 of ACI 318-11, does not exceed the design shear strength of the connection. When shear reinforcement is required, $v_{s} \geq 2 \sqrt{ } f_{c}^{\prime}$, psi $\left(0.17 \sqrt{ } f_{c}^{\prime}\right.$, MPa).

The need to ensure adequate lateral drift capacity of slabcolumn connections often leads to the use of shear reinforcement, typically in the form of headed shear studs. According to ACI 318-11, shear stud reinforcement must be arranged such that the stud spacing within the first peripheral line of studs does not exceed $2 d$, where $d$ is the effective depth of the slab. The spacing between peripheral lines, on the other hand, is limited to $3 d / 4$ for connections with a shear stress of up to $6 \sqrt{ } f_{c}^{\prime}$, psi $\left(0.50 \sqrt{ } f_{c}^{\prime}, \mathrm{MPa}\right)$ and to $d / 2$ for higher shear stresses.

The fact that no peripheral spacing limit is given for studs outside the first peripheral line allows the arrangement of shear stud reinforcement in a cruciform pattern, which has become the preferred option in the United States. This contrasts with Eurocode 2 (Comité Européen de Normalisation 2004), which limits both the spacing of studs in several peripheral lines to $1.5 d$ and the width of the slab assumed to be engaged by the shear studs. The result is a more uniform distribution of shear reinforcement around the column than obtained using a cruciform pattern.

Results from the test of a large-scale slab-column connection under combined gravity load and biaxial lateral displacements (Cheng et al. 2010), which failed while being cycled at a drift of $1.15 \%$ in each principal loading direction (1.65\% resultant drift due to biaxial displacements), have recently brought into question the deformation capacity of slab-column connections reinforced with shear studs. In this particular test, shear generated by simulated gravity loads

ACI Structural Journal, V. 112, No. 3, May-June 2015.

MS No. S-2013-400.R3, doi: 10.14359/51687408, received June 12, 2014, and reviewed under Institute publication policies. Copyright (C) 2015, American Concrete Institute. All rights reserved, including the making of copies unless permission is obtained from the copyright proprietors. Pertinent discussion including author's closure, if any, will be published ten months from this journal's date if the discussion is received within four months of the paper's print publication. 
(calculated from the forces imposed on the specimen using equilibrium) corresponded to half of the connection capacity without shear studs (that is, $v_{u g} / v_{c}=50 \%$ ). Shear studs were designed to resist the shear stress caused by gravity load and lateral displacements (through moment transfer) in each perpendicular direction, which was calculated using the eccentric shear-stress model (Section 21.13.6(a) of ACI 318-11).

The low drift capacity exhibited by the specimen tested by Cheng et al. (2010) made clear the need for additional experimental data on the behavior of slab-column connections with various amounts and configurations of headed shear studs to better evaluate the ability of shear stud reinforcement to increase drift capacity of slab-column connections subjected to gravity load and earthquake-induced displacements. The experimental program reported herein was intended to help address this need.

\section{RESEARCH SIGNIFICANCE}

Results from tests of large-scale slab-column connections under combined gravity load and biaxial lateral displacement reversals are presented, which allow a better understanding of the effect of shear stud amount and layout on the behavior of slab-column connections subjected to combined gravity load and earthquake-type loading.

\section{EXPERIMENTAL PROGRAM}

\section{Overall specimen configuration}

Four nearly full-scale slab-column subassemblies with nominally identical geometry were tested under combined gravity loading and biaxial lateral displacements. Specimen design was based on a previous experimental investigation by Cheng et al. (2010). Elevation and plan views of the specimen are shown in Fig. 1. Each specimen consisted of a $17 \mathrm{ft}$ $(5.2 \mathrm{~m})$ square, 6 in. $(0.15 \mathrm{~m})$ thick slab supported by a fullstory 16 in. $(0.41 \mathrm{~m})$ square column with a clear height of $10 \mathrm{ft}-3$ in. $(3.1 \mathrm{~m})$. The column extended $5 \mathrm{ft}(1.5 \mathrm{~m})$ above the slab. The column base was anchored into a heavily reinforced concrete base block that was fixed to the laboratory floor. A top block was cast monolithically on top of the column for application of lateral displacements. A point of inflection was imposed at the top of the top block.

The slab was vertically supported by hydraulic actuators at each corner. To reduce slab edge vertical deflections and thus make the slab edge support conditions closer to a continuous roller support, steel tube sections were fastened to the slab along its perimeter (Fig. 1(b)). Even though it was not possible to realistically simulate the boundary conditions along the slab perimeter, the slab dimensions were large enough (distance from inner edge of steel tube to closest column face was equal to 12.7 slab thicknesses) to minimize the effect on connection behavior.

\section{Specimen design}

In the following, a brief description of the design of the specimens is provided. More detailed information can be found elsewhere (Matzke et al. 2013).

Slab flexural design-The slab-column connection in the test specimens was designed assuming it was not part of the seismic-force-resisting system. The load combination used

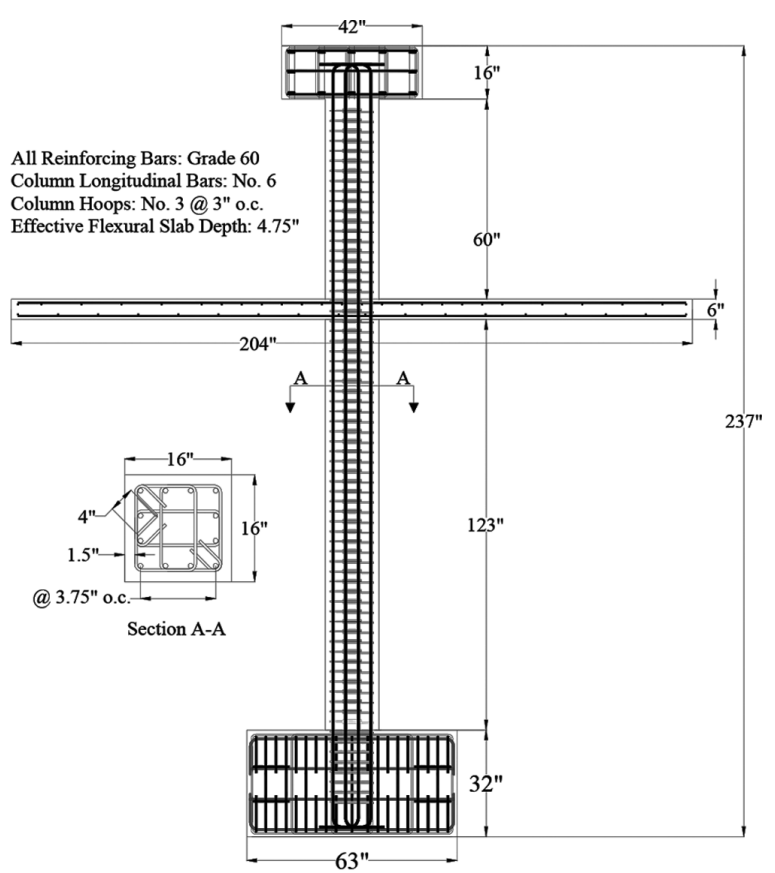

(steel tube sections not shown for clarity)

(a) Elevation view

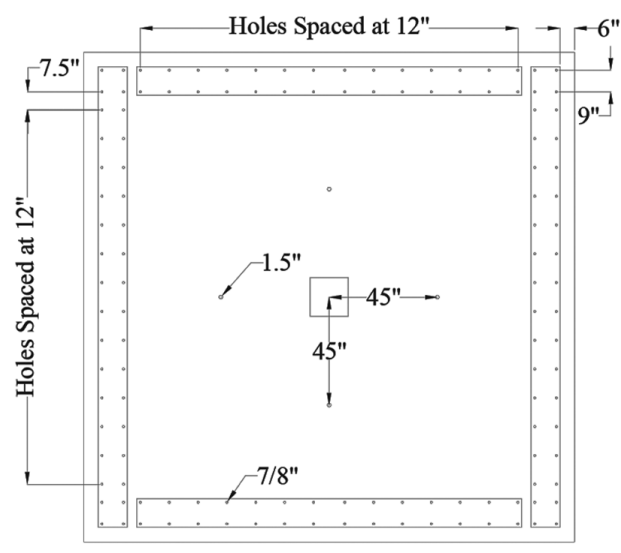

(b) Plan view

Fig. 1-Typical geometry of specimens. (Note: $1 \mathrm{in} .=25.4 \mathrm{~mm}$.)

for calculation of the gravity shear stress was $1.2 D+0.5 L$, as specified in Section 21.13.6 of ACI 318-11 for structures other than "garages, areas occupied as places of public assembly, and all areas where $L$ is greater than $100 \mathrm{lb} / \mathrm{ft}^{2}$ $\left[4.8 \mathrm{kN} / \mathrm{m}^{2}\right]$." Assuming a ratio between dead and live load of 2 , the magnitudes of dead and live loads used in design were selected so that the average shear stress on the critical section of the connection (at $d / 2$ from the column faces) was equal to $2 \sqrt{ } f_{c}^{\prime}$, psi $\left(0.17 \sqrt{ } f_{c}^{\prime}, \mathrm{MPa}\right)$, resulting in a gravity shear ratio of $50 \%$. Gravity shear ratio was calculated as the ratio of gravity shear stress to the nominal shear-stress capacity provided by the concrete, $v_{c}$, assuming $v_{c}=4 \sqrt{ } f_{c}^{\prime}$, psi $\left(0.34 \sqrt{ } f_{c}^{\prime}\right.$, MPa). For design purposes, the compressive strength of the concrete and yield strength of the flexural reinforcement were assumed to be 5000 and $60,000 \mathrm{psi}(34.5$ and $414 \mathrm{MPa})$, respectively.

Design moments in the slab were determined based on the calculated dead and live load intensities using the Direct 
Design Method outlined in Section 13.6 of ACI 318-11. Reinforcement layouts, shown in Fig. 2, were nominally identical in each principal direction with an average effective depth $d$ of 4.75 in. $(0.12 \mathrm{~m})$. Reinforcement in the column strip consisted of No. 4 (No. 13M) bars spaced at 6 in. $(0.15 \mathrm{~m})$, resulting in a tensile reinforcement ratio of $0.6 \%$ based on the slab overall thickness $(0.7 \%$ based on the average effective slab depth). As shown in Fig. 2, two bottom bars in each direction passed continuously through the column core, as required in Section 13.3.8.5 of ACI 318-11.

Connection shear design-All four connections were designed to resist shear stresses on the critical perimeter induced by gravity loads (corresponding to a $50 \%$ gravity shear ratio) and expected moment transferred into the column (so-called "unbalanced" moment), according to ACI 318-11, Section 21.13.6(a). A moment transfer of 1400 kip-in. (160 kN-m) was assumed based on results from previous experiments by Cheng et al. (2010) of nearly identical specimens. According to ACI $318,40 \%$ of this moment was assumed to be transferred through shear, resulting in a combined shear stress $v_{u} \cong 4.9 \sqrt{ } f_{c}^{\prime}$, psi $\left(0.41 \sqrt{ } f_{c}^{\prime}, \mathrm{MPa}\right)$.

For design of the shear stud reinforcement (shown in Fig. 3), a yield strength of $55 \mathrm{ksi}(410 \mathrm{MPa})$ was used. Stud rails for Specimens B1 and B2 were arranged in a cruciform pattern, with rails placed orthogonally to each column face. The shear design for the connection in Specimen B1 was based on the assumption of zero concrete contribution to shear capacity $\left(v_{c}=0\right)$, resulting in the layout shown in Fig. 3(a) with a shear stud spacing perpendicular to each column face of $0.5 \mathrm{~d}$. Specimen B2 was reinforced with shear studs in a cruciform layout (Fig. 3(a)) proportioned such that $v_{s}=3.5 \sqrt{ } f_{c}^{\prime}$, psi $\left(0.29 \sqrt{ } f_{c}^{\prime}, \mathrm{MPa}\right)$ extending over $4.4 h$ from the column face, where $h$ is the slab thickness. This shear reinforcement design satisfied the minimum amount required by Section 21.13.6 of ACI 318-11 if no shear stress or drift capacity check is performed. For this specimen, the shear stud spacing perpendicular to each column face was $0.75 d$.

Specimen B3 was reinforced with the same number of stud rails at the same stud spacing as Specimen B1; however, four of the 12 stud rails were placed at the column corners, oriented at a 135-degree angle to the column faces (Fig. 3(b)). The other eight rails were placed perpendicular to the column faces (two per column face). The purpose of using this arrangement was to provide a more uniform shear stud spacing around the column and thereby increase the region of the connection reinforced in shear.

A total of 20 stud rail assemblies were used in the connection of Specimen B4 (Fig. 3(b)), which led to $v_{s}=7.8 \sqrt{ } f_{c}^{\prime}$, psi $\left(0.65 \sqrt{ } f_{c}^{\prime}, \mathrm{MPa}\right)$. As in Specimen B3, one rail was placed at each column corner at a 135-degree angle to the faces of the column. To minimize interference with slab reinforcement, the stud spacing on these diagonally placed assemblies was increased by a factor of $\sqrt{2}$ so that the studs would lie on an orthogonal grid. This shear stud layout led to a lower maximum stud spacing in each peripheral row compared to that in Specimen B3.

Shear studs used in Specimens B1 and B2 were provided by one supplier, whereas the studs used in Specimens B3 and B4 were provided by another supplier. There were

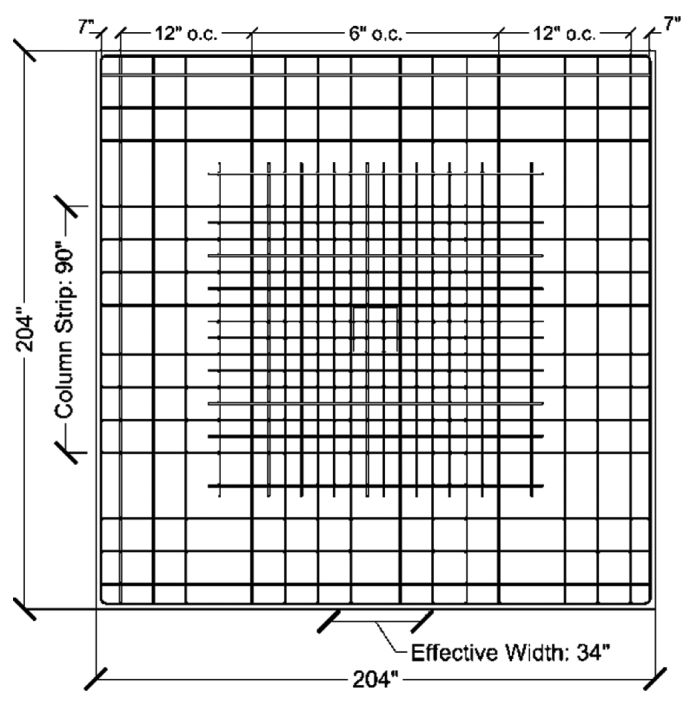

(a) Top layer of reinforcement

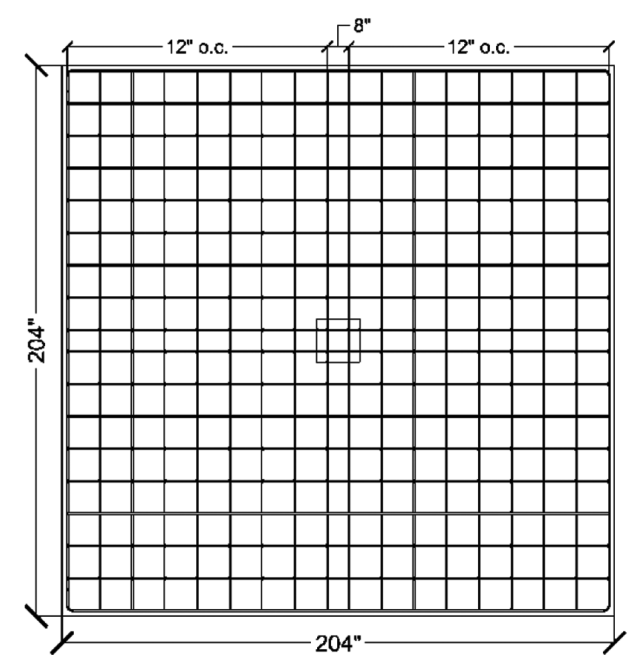

(b) Bottom layer of reinforcement

Fig. 2-Slab flexural reinforcement layouts. All bars are No. 4 (D13) Grade 60. (Note: 1 in. $=25.4 \mathrm{~mm}$ )

minor differences in the base plate dimensions for the two suppliers, but the stud dimensions remained identical, with a head area equal to 10 times the shank area.

Column design-The column was designed to remain elastic except at the base. Twelve No. 6 (No. 19M) bars were used as longitudinal reinforcement, which represented a reinforcement ratio $\rho_{g}=2.1 \%$. Sufficient transverse reinforcement was provided to prevent any significant shear-related damage throughout the tests. Transverse reinforcement was uniformly spaced at $3 \mathrm{in}$. (76 $\mathrm{mm}$ ) along the column height, with each layer of transverse reinforcement consisting of three No. 3 (No. 10M) closed hoops (four legs in each direction), as shown in Fig. 1(a).

\section{Material properties}

Concrete - Concrete was supplied by a local concrete supplier. The same mixture design was used throughout the project. The concrete was specified to have a compressive strength of 5000 psi (34 MPa), a slump of 6 in. (150 mm), 

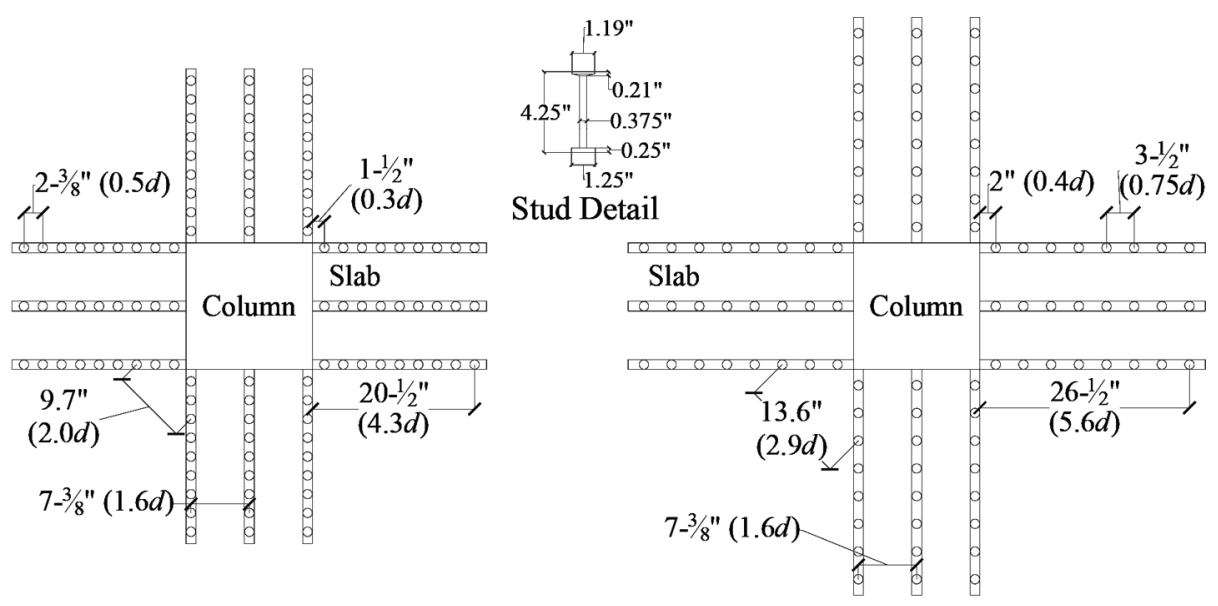

(a) Specimens B1 (left) and B2 (right)

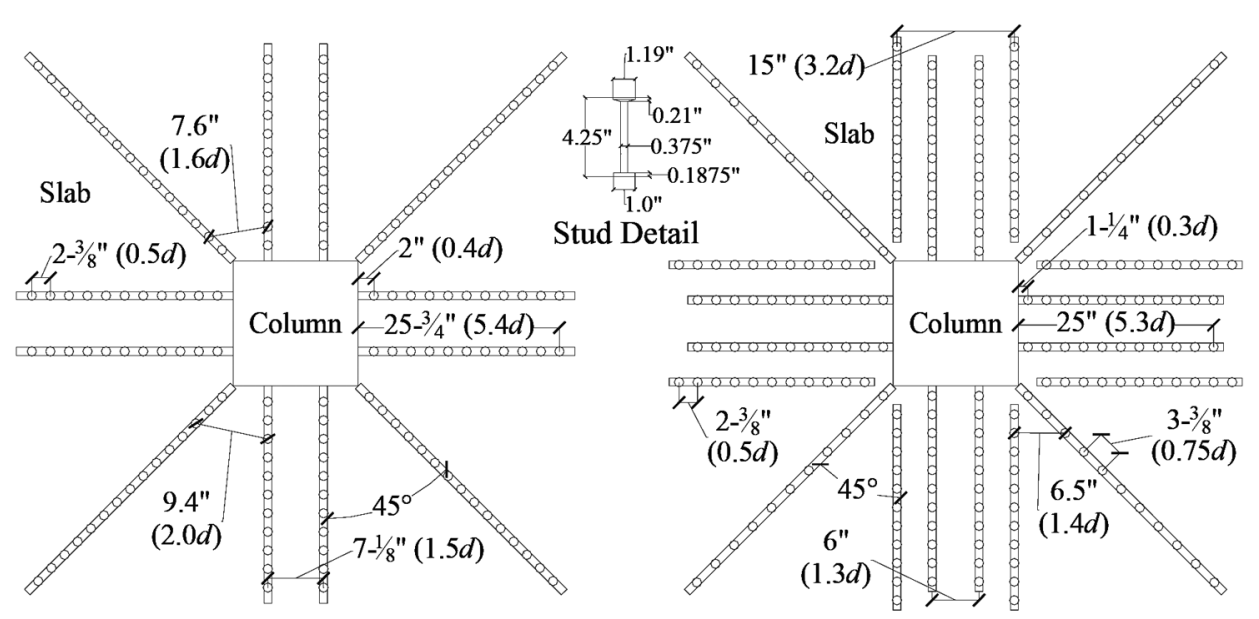

(b) Specimens B3 (left) and B4 (right)

Fig. 3-Shear stud dimensions and layout. (Note: $1 \mathrm{in} .=25.4 \mathrm{~mm}$.)

and maximum aggregate size of $3 / 8$ in. $(10 \mathrm{~mm})$. The mixture proportions by weight of cement, water, sand, and bedrock aggregate were 1:0.48:2.05:2.5, respectively. The measured concrete compressive strength, taken as the average compressive strength of three $4 \times 8$ in. $(100 \times 200 \mathrm{~mm})$ concrete cylinders a day before testing, was 5900, 4900, 5700, and $6100 \mathrm{psi}$ $(41,34,39$, and $42 \mathrm{MPa})$ for the slabs in Specimens B1 through $\mathrm{B} 4$, respectively. All cylinders were kept in their molds at room temperature next to the slab specimens until testing.

Reinforcing steel-All reinforcing bars were uncoated Grade 60 steel compliant with ASTM A615, Type 2, requirements. The yield and ultimate strengths of the reinforcing bars used in each specimen were determined through tests of three $2 \mathrm{ft}(0.61 \mathrm{~m})$ long bars of each size. The average yield strengths of the flexural reinforcement in the slabs of Specimens B1 through B4 were 67.6, 70.0, 64.7, and $67.4 \mathrm{ksi}(466,483,446$, and $465 \mathrm{MPa}$ ), and the measured ultimate strengths were 110,112 , 100 , and $109 \mathrm{ksi}(760,771,690$, and $752 \mathrm{MPa})$, respectively.

Shear stud reinforcement-The shear studs used in all four specimens were made with steel with a specified yield strength of $55 \mathrm{ksi}(379 \mathrm{MPa})$. Yield and ultimate strengths reported by the manufacturer that supplied the shear studs for Specimens B1 and B2 were 70.0 and $79.8 \mathrm{ksi}$ (482 and $550 \mathrm{MPa}$ ), respectively. A different vendor supplied the shear studs used in Specimens B3 and B4. No strength test data were available for the shear studs used in these two specimens; however, strain gauge data obtained during testing were consistent with yielding occurring at strains greater than 0.002. Therefore, the yield stress for the shear studs used in Specimens B3 and B4 appears to have been greater than $60 \mathrm{ksi}(420 \mathrm{MPa})$, the maximum yield stress permitted by ACI 318-11 for shear stud design.

\section{Loading method and sequence}

Axial force and lateral displacements were applied at the top of the column through the use of a "rigid" crosshead. An axial load of $140 \mathrm{kip}(620 \mathrm{kN})$, which is approximately equal to $0.10 A_{g} f_{c}^{\prime}$ when calculated using the specified concrete strength, was applied to the top of the column while the slab corners were free to displace. After applying axial load to the column, the movement of the vertical actuators supporting the slab corners was restrained. In addition to the self-weight of the slab, a simulated gravity load was imposed on the slab using four prestressing strands $(1 / 2 \mathrm{in}$. [13 mm] diameter, Grade 270, seven-wire, low-relaxation strands) at $7.8 d$ (45 in. [1.14 m]) from each column face (Fig. 1(b)). The force in each strand was monitored with a load cell. The selfweight of the slab and fixtures, combined with the applied 
load in the strands, resulted in an average shear stress of $2 \sqrt{f_{c}}$, psi $\left(0.17 \sqrt{ } f_{c}^{\prime}, \mathrm{MPa}\right)$ (gravity shear ratio of $\left.50 \%\right)$ on the critical section of the connection (at $d / 2$ from each column face). The value of $f_{c}^{\prime}$ used for calculating the target shear stress was based on the average cylinder compressive strength measured the day prior to slab testing. After application of gravity load to the slab, the axial load in the first story of the column was approximately $200 \mathrm{kip}(890 \mathrm{kN})$.

The method used for simulating gravity load in this test program was substantially different than that used in most test programs of slab-column connections with shear stud reinforcement, where jacking of the column was predominantly used to generate the desired connection shear. While convenient, this method has important drawbacks, such as an unrealistic moment-shear relationship in the slab and the need to further jack the column in order to maintain gravity shear, which could lead to connection deformed shapes far from those expected in a building structure subjected to earthquake-induced lateral displacements. Information on test setups used by various investigators can be found in Cheng (2009).

Lateral displacements were applied to the top block through the crosshead. The displacement path for each drift cycle followed the cloverleaf pattern shown in Fig. 4(a). Target drifts for each cycle are shown in Fig. 4(b). These drifts represent total specimen drifts equal to the lateral displacement at the top of the column divided by the specimen height (17 ft-1 in. [5.21 m]). Drift values reported herein correspond to this total specimen drift. Lateral displacements at the level of the slab, however, were also measured in order to calculate "first-story" and "half secondstory" drifts, which tended to be approximately $20 \%$ lower and $30 \%$ higher than the total specimen drift, respectively.

Throughout each drift cycle, a steady, but relatively small, decrease in the applied gravity load, due primarily to slab damage, was observed. At the end of each drift cycle, the strands were reloaded to forces corresponding to the target gravity shear ratio. At higher drifts, however, a large reduction in the gravity shear (approximately $20 \%$ of the target gravity shear) was observed within each cycle as the slab accumulated damage. When this occurred, the test was paused within a cycle and strand loads were adjusted to reestablish the target gravity shear ratio before resuming the test. The tests were terminated when excessive damage had developed in the slab at the connection and/or when the applied gravity shear could not be restored to its target level.

\section{Overall behavior}

\section{EXPERIMENTAL RESULTS}

The four specimens behaved similarly in response to initial application of gravity loads and to lateral displacements up to approximately $1.60 \%$ drift (Fig. 5). Gravity load application resulted in tensile strains ranging from 0.00035 to 0.0005 in the top mat of reinforcement approximately $2 \mathrm{in}$. $(50 \mathrm{~mm})$ from the column faces. However, these values do not account for initial strains resulting from the self-weight of the slab and fixtures, which were not measured. Linear variable differential transformer (LVDT) measurements indicated that strains large enough to cause cracking developed on the top and bottom surfaces of the slab within one slab

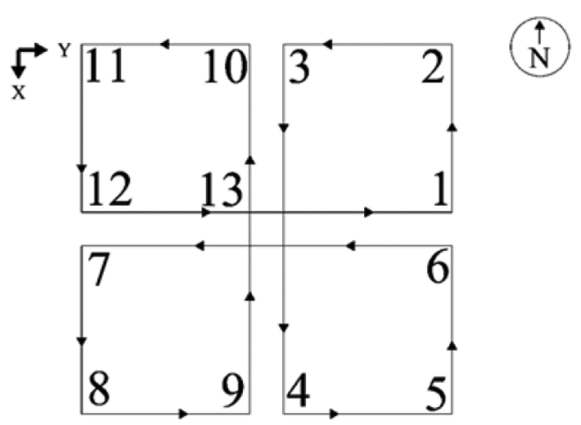

(a) Cloverleaf displacement followed for each drift cycle

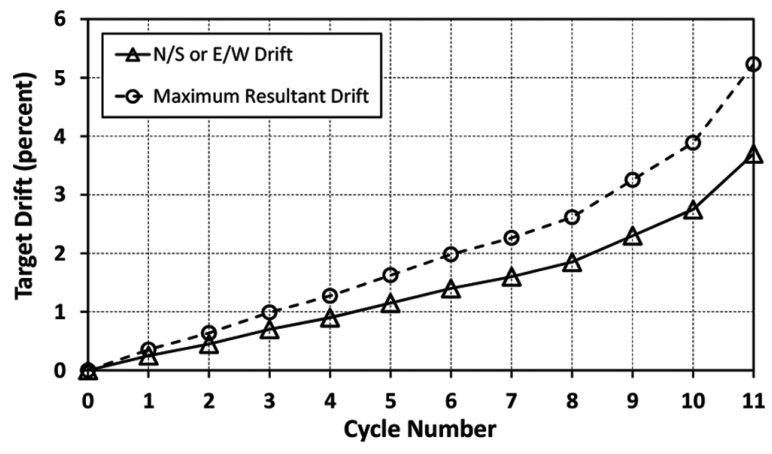

(b) Target drifts for each loading cycle

Fig. 4-Loading pattern and target drifts.

depth of the column during the cycle to $0.25 \%$ drift. Tensile strains exceeding the reinforcement yield strain were first measured in the top mat reinforcement near the faces of the column at approximately $0.70 \%$ drift. By $0.90 \%$ drift, strains indicating extensive yielding in the top mat of reinforcement were recorded over the column width (this yielding extended over a width of approximately two times the slab thickness from the column faces by the end of the tests).

The flexural capacity of the slab governed the lateral strength of the specimens, leading to relatively constant peak strengths during the cycles between 0.90 and $1.60 \%$ drift. Damage growth at these drift levels consisted primarily of widening flexural cracks as yielding of the slab flexural reinforcement became more extensive. Strain data from instrumented shear studs gave evidence that diagonal cracking in the slab first occurred at approximately $1.15 \%$ drift. The shear stud reinforcement, however, was effective at restraining the growth of these cracks and delaying a punching failure. This led to a connection behavior dominated by flexural yielding during the cycles up to $1.60 \%$ drift $(2.25 \%$ resultant drift for biaxial lateral displacements).

In all four specimens, punching-shear-related damage was first observed during the cycle at $1.85 \%$ drift. Subsequently, extensive flexural cracking and concrete degradation due to inadequate concrete confinement were observed as the connections underwent several cycles of inelastic deformation reversals. Details of the behavior of the specimens after punching-shear-related damage was first observed, which varied depending on the shear reinforcement design, are briefly described in the following sections.

Specimen B1-The first punching shear-related crack in Specimen B1 (Fig. 6) was observed on the top face of the 

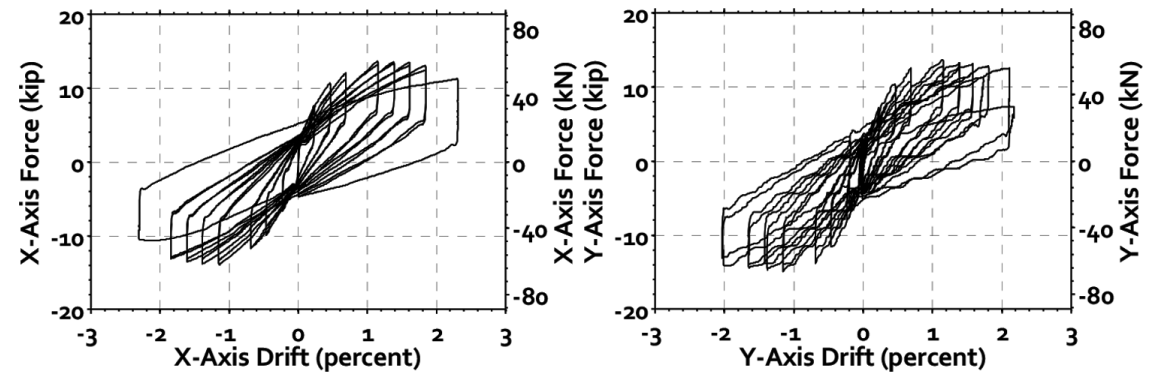

(a) Specimen B1
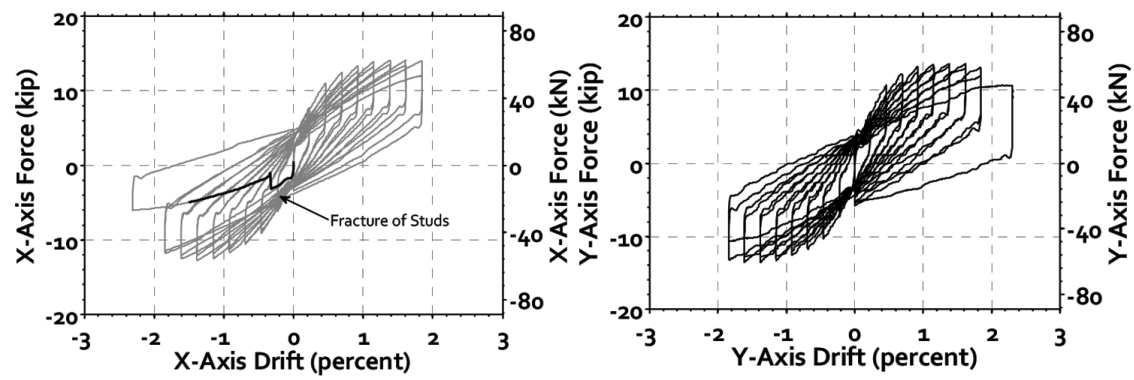

(b) Specimen B2
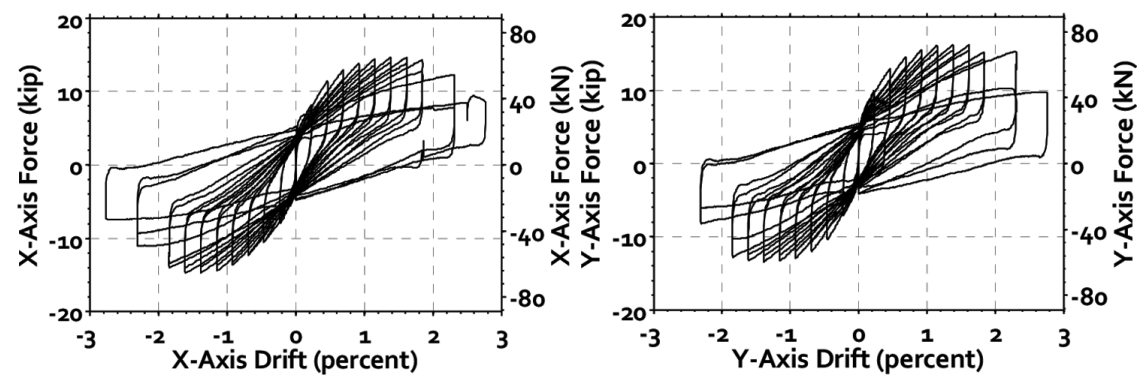

(c) Specimen B3
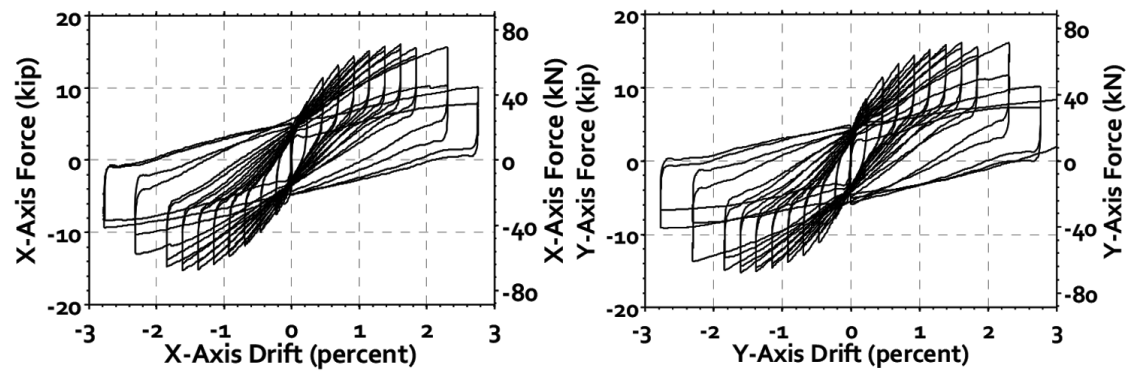

(d) Specimen B4

Fig. 5-Lateral force versus total specimen drift response.

slab east of the column during the $1.85 \%$ drift cycle at Point 8 in the cloverleaf load pattern. This crack, however, did not translate into any change in the overall hysteresis behavior of the specimen (Fig. 5(a)). When displaced to $2.30 \%$ drift, a loss of lateral load capacity occurred, as punching shearrelated damage and severe concrete degradation was observed along the west, south, and east faces of the connection (refer to Fig. 7 for a photograph of this region taken after completion of test). The slab also dropped approximately 1 in. $(25 \mathrm{~mm})$ relative to its initial elevation on the column along these three sides of the connection. In the northeast and northwest corners of the connection, however, a different slab damage pattern developed that consisted of long cracks extending from the column corners approximately 36 in. $(0.90 \mathrm{~m})$ toward their respective corners of the slab (Fig. 8). These cracks tended to "isolate" the north region of the slab, which explains the relatively sound condition of the concrete in this area and the absence of a substantial drop with respect to the column, except for the bottom slab cover. After returning to zero lateral displacement 


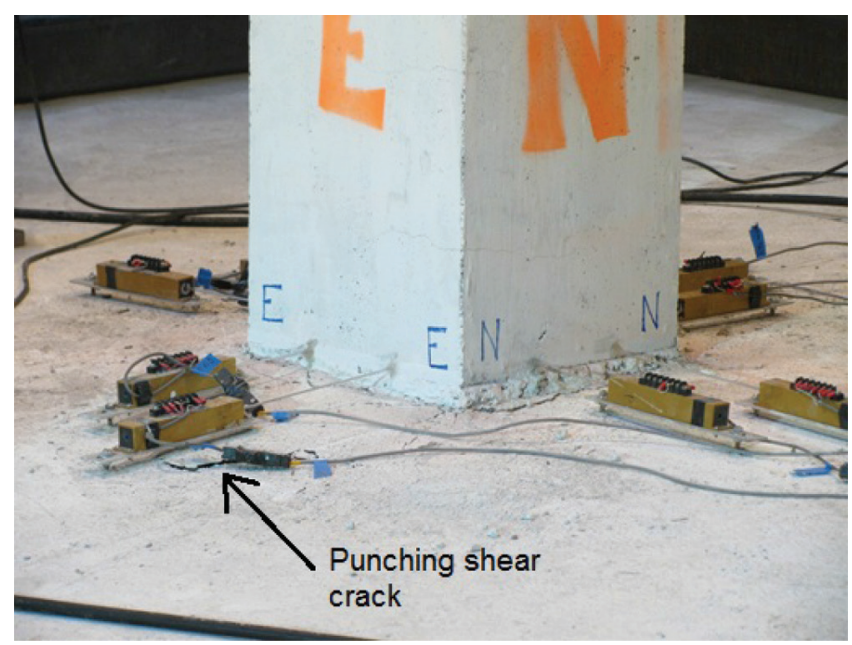

Fig. 6-Specimen B1 at Point 8 of 1.85\% drift cycle, when first evidence of punching shear-related cracking was observed.

following loading to Point 5 of the $2.30 \%$ drift cycle, the test was terminated because the specimen could no longer support gravity loads.

The severe concrete degradation observed on the east, south, and west sides of the connection indicates that the shear studs, although potentially active in bridging diagonal cracks, did not provide the confinement necessary to maintain the integrity of the slab concrete and allow shear transfer at large drifts. As evidenced by the photograph in Fig. 7, which was taken after removal of loose concrete, the studs on the east side of the connection were only effective at maintaining the integrity of the concrete near the stud heads. Concrete between stud rails was severely degraded. In cases where the head of the first stud in each orthogonal row rested directly on top of a slab flexural bar, it was observed that the slab bar effectively anchored the stud and prevented it from dropping with the slab. As a result, significant bending of the supporting rail and shear stud was often observed as adjacent studs away from flexural bars dropped with the slab (in Fig. 7, stud head rotation can be seen in the first stud visible on the south face of the column).

Specimen B2-The first cracks in Specimen B2 associated with the beginning of a punching failure developed during the $1.85 \%$ drift cycle at Point 8 , as was the case for Specimen B1. By the end of the $1.85 \%$ drift cycle, the bottom of the slab had dropped approximately 0.25 in. $(6 \mathrm{~mm})$ down the column and a failure surface appeared to have formed around the perimeter of the connection. While moving from Point 1 to Point 2 of the $2.30 \%$ drift cycle, the slab dropped abruptly, as much as $3 / 4$ in. $(19 \mathrm{~mm})$ at the south and west sides of the connection. This event was associated with a severe drop in applied gravity shear and a slight but sudden decrease in applied lateral load in the x-direction (refer to the portion of hysteresis response highlighted in black in Fig. 5(b)), likely caused by the fracture of several studs at the base weld that was revealed after the test was terminated. These stud fractures, along with the severe concrete degradation in the connection region, led to a substantial loss of stiffness and gravity load capacity of the specimen. As a result, the test was terminated.

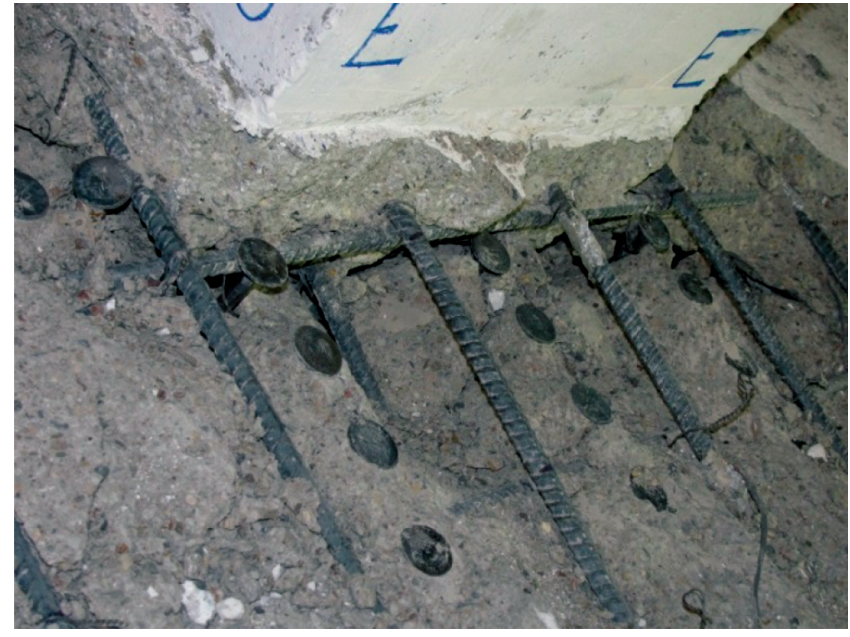

Fig. 7-Void in connection region, typical of damage at east, west, and south column faces of Specimen B1.

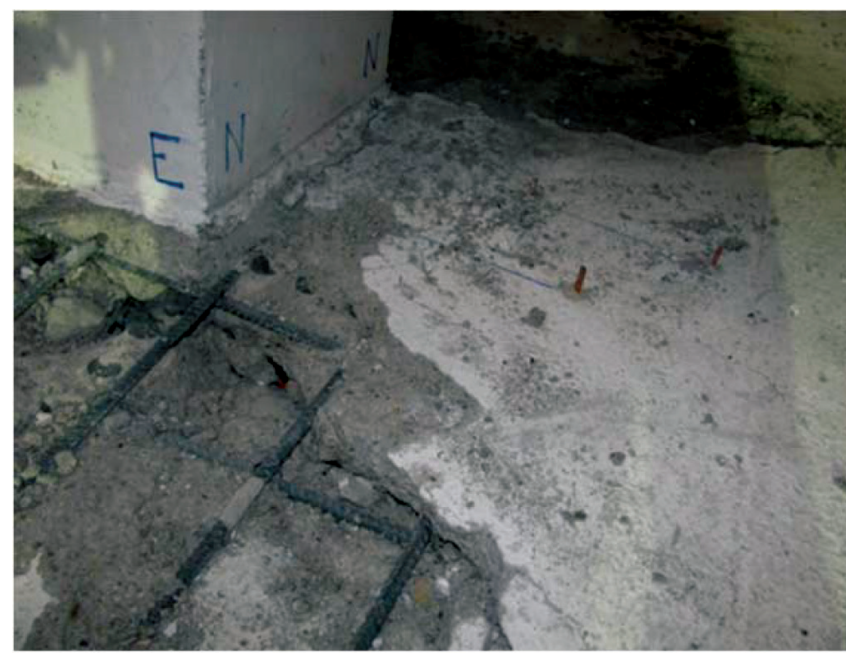

Fig. 8-Damage in slab north of column in Specimen B1.

Once all loose concrete was removed from the connection of Specimen B2 following completion of the test, what remained was a traditional punching shear failure surface west and south of the column, and a completely void area within a distance from the column face approximately equal to the slab effective depth $d$ north and east of the column, as shown in Fig. 9. As in Specimen B1, such degradation of concrete is indicative of the lack of confinement provided by the shear studs.

Specimen B3-Punching-shear-related cracking first appeared on the west face of the connection of Specimen B3 approximately $2 d$ away from the column face after loading to Point 2 during the $1.85 \%$ drift cycle. At the end of the $1.85 \%$ drift cycle, an approximately $1 / 4$ in. $(6 \mathrm{~mm})$ vertical drop of the slab was measured on the underside of the connection. While loading to Point 2 of the $2.30 \%$ drift cycle, strains indicative of yielding were measured in a stud south-west of the column. The connection continued to support the applied gravity loads during the remainder of the $2.30 \%$ drift cycle, although punching-shear-related damage became increasingly severe and extended around most of the connection perimeter. 
As the slab dropped during the cycle to $2.30 \%$ drift (to more than 1 in. [25 mm] by the end of the cycle), rail assemblies displaced downward with the slab relative to the column, except where the first stud of a rail assembly was anchored by one of the slab bars passing through the column. This improved stud anchorage caused the base rail to dowel between the first and second shear stud, leading to some contribution from the base rail to shear resistance. Also during the $2.30 \%$ drift cycle, the slab began to twist around the axis of the column as damage accumulated in the connection. The test was terminated after reaching Point 4 in the cycle to $2.75 \%$ drift due to excessive twisting of the slab relative to the column (approximately 0.1 radians about the longitudinal axis of the column).

The drift capacity of Specimen B3 was limited by severe concrete degradation in the slab within the first two rows of studs (within $d$ from the column faces) around the column perimeter. Only the concrete within the diameter of the head of a few studs remained relatively sound, which, as in Specimens B1 and B2, is indicative of the poor confinement provided by the shear studs.

Specimen B4-The first crack associated with the initiation of a punching shear failure in Specimen B4, located approximately $2 d$ from the west and south column faces, was observed when loading to Point 11 during the $1.85 \%$ drift cycle. While loading to Point 5 of the $2.30 \%$ drift cycle, inelastic strains were recorded in a stud northwest of the column and the lateral strength of the specimen began to decrease. After loading to Point 8 of the $2.30 \%$ drift cycle, punching-shear-related damage had extended around the perimeter of the column and the lateral strength of the specimen had decreased to approximately half of the peak strength. Although the connection continued to support the applied gravity loads, the slab dropped approximately $1 \mathrm{in}$. $(25 \mathrm{~mm}$ ) from its original position by the end of the $2.30 \%$ drift cycle and continued to displace downward with continued cycling, reaching 2 in. (50 mm) of vertical displacement by the end of the $2.75 \%$ drift cycle. All but one of the shear stud assemblies completely dropped away from the column with the outer portion of the slab. The exception, as in Specimen B3, was a rail assembly in which the first stud was anchored by a top slab bar passing through the column.

Removal of concrete in the connection of Specimen B4 was more difficult than in the three previous specimens, indicating the concrete was more sound at the end of the test. This was likely due to the increased number and tighter spacing of shear studs, which provided improved confinement to the concrete.

\section{Column base rotations}

The first story of the columns was subjected to axial forces of approximately $200 \mathrm{kip}(890 \mathrm{kN})$, or between $0.1 A_{g} f_{c}^{\prime}$ and $0.13 A_{g} f_{c}^{\prime}$, where $A_{g}$ is the cross-sectional area of the column and $f_{c}^{\prime}$ is the cylinder compressive strength. Maximum shear stresses (in each principal loading direction) of approximately $0.9 \sqrt{ } f_{c}^{\prime}$, psi $\left(0.08 \sqrt{ } f_{c}^{\prime}\right.$, MPa) were imposed on the column. Flexural yielding at the base of the column first occurred at a rotation of approximately $0.005 \mathrm{rad}$ (measured over a distance from the top of the foundation equal to the

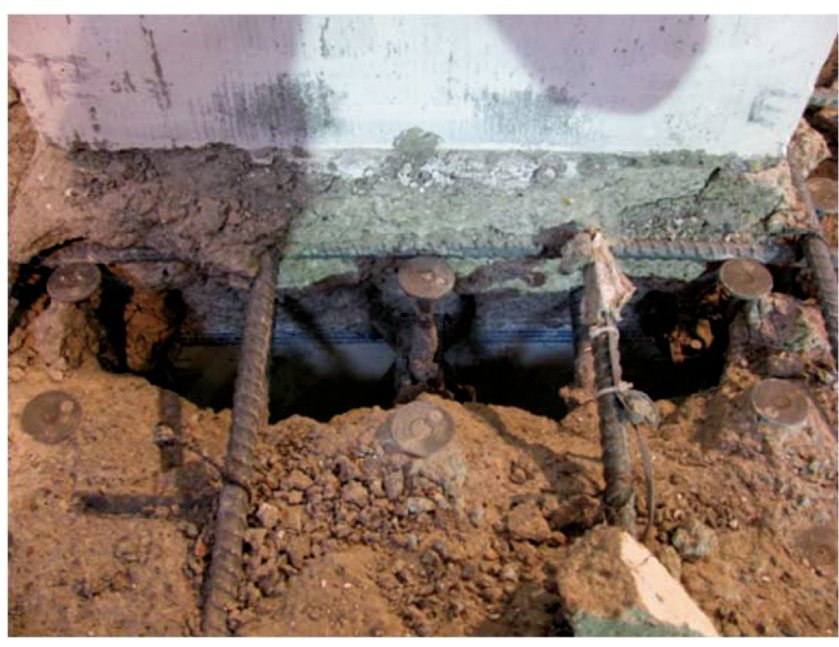

Fig. 9-East side of connection region in Specimen B2 after severely degraded concrete had been removed by hand.

effective depth of the column) and the peak moment at the column base occurred at a column rotation of approximately $0.007 \mathrm{rad}$. Maximum calculated rotation for bending in each principal direction ranged approximately from 0.008 to $0.011 \mathrm{rad}$ for Specimens B1 through B3, whereas the column base of Specimen B4 underwent rotations of up to approximately $0.016 \mathrm{rad}$ because this specimen was subjected to the largest lateral displacement. No major damage was observed in the columns, although cover spalling at the column base was observed at the end of each test.

\section{Shear demand versus nominal shear strength}

The strength of each specimen and, therefore, the shear stress imposed on the critical section in the slabs, was limited by the flexural strength of the slab. The peak combined shear stress on the critical section (from gravity load and moment transfer) in each principal loading direction was similar in all four specimens, with calculated values that ranged from $4.1 \sqrt{ } f_{c}^{\prime}$ to $4.4 \sqrt{ } f_{c}^{\prime}$, psi $\left(0.34 \sqrt{ } f_{c}^{\prime}\right.$ to $0.37 \sqrt{ } f_{c}{ }_{c}^{\prime}$, MPa). Likewise, the peak shear stress at any point on the critical section due to biaxial bending was consistent, with values ranging from $5.8 \sqrt{ } f_{c}^{\prime}$ to $6.2 \sqrt{ } f_{c}^{\prime}$, psi $\left(0.48 \sqrt{ } f_{c}^{\prime}\right.$ to $\left.0.52 \sqrt{ } f_{c}^{\prime}, \mathrm{MPa}\right)$.

The nominal shear strengths of all four connections, calculated using the measured concrete strength, the maximum yield strength permitted by ACI 318-11 for shear studs of 60 ksi (420 MPa), and not considering the upper shear-stress limit in ACI 318, were 1.9, 1.6, 1.9, and 2.6 times the peak combined shear stresses calculated for loading in either the $\mathrm{x}$ - or $\mathrm{y}$-axis direction for Specimens B1, B2, B3, and B4, respectively. Neglecting the contribution of the concrete, the shear reinforcement contribution $v_{s}$ was still greater than the combined stress demand in either the $\mathrm{x}$ - or $\mathrm{y}$-axis loading directions in Specimens B1, B3, and B4. When compared to the imposed combined biaxial shear stresses, the ratio of nominal strength to peak shear-stress demand was 1.4, 1.1, 1.4, and 1.9 for Specimens B1, B2, B3, and B4, respectively. In the case of Specimen B4, $v_{s}$ alone was approximately $40 \%$ greater than the peak shear stress calculated for biaxial moment transfer. It should be mentioned that the reported yield strength of the shear studs used in Specimens B1 and 
B2 was $70.0 \mathrm{ksi}(482 \mathrm{MPa})$. A slab reinforced with shear studs with actual yield strength closer to the specified yield stress may be more vulnerable to shear degradation than Specimens B1 and B2.

The use of shear studs in sufficient amounts to resist the entire shear demand due to applied gravity load and moment transfer in each perpendicular loading direction - that is, $v_{c}=0$ (Specimens B1, B3 and B4), or satisfying the minimum amount of shear reinforcement in Section 21.13.6 of ACI 318-11 when neither a drift nor a combined shear-stress check is performed (Specimen B2, where $v_{s}=$ $3.5 \checkmark f_{c}^{\prime}$, psi [0.29 $\left.\sqrt{f_{c}}{ }^{\prime}, \mathrm{MPa}\right]$ ), led to a substantial increase in drift capacity compared to a nearly identical specimen with minimum shear reinforcement tested by Cheng et al. (2010), which failed when loaded to a drift of $1.15 \%$ in each perpendicular direction. Such an increase in shear stud reinforcement, however, did not prevent severe concrete degradation in the slab adjacent to the column at large drift levels, which ultimately limited the drift capacity of the specimens.

\section{Slab-column flexural rotations}

Linear variable differential transformers (LVDTs) were fixed to the top and bottom of the slab at both $d$ and $2 d$ from each column face (Fig. 10) so that flexural rotations in the slab could be calculated. In general, all four specimens exhibited a similar behavior in terms of flexural rotations. Prior to evidence of slab punching, peak calculated flexural rotations were between 0.03 and 0.04 radians. Figure 11 shows the slab moment about the $y$-axis plotted versus rotations calculated $d$ and $2 d$ from the north column face of Specimen B2. The similarity between the two plots is typical of all four column faces in all four specimens and indicates that most or all inelastic flexural deformations concentrated within $d$ from the column faces.

\section{Shear stud strains}

Axial strain in the stud shanks was monitored in several shear studs in each specimen (the layout of studs is shown in Fig. 3). Beyond 1.5d from the column periphery, tensile strain readings in all instrumented shear studs never exceeded 0.0018 , and were typically less than 0.001 . Large increases in strain were observed in studs located in the first three peripheral lines during the cycles at $1.15 \%$ drift, likely indicating the formation of diagonal cracks. During subsequent cycles up to $1.85 \%$ drift, the peak strains in the first three rows of shear studs steadily increased. The fact that stud strains increased while the connection shear-stress demand remained relatively constant suggests an increase in the role played by shear reinforcement in resisting connection shear. The maximum measured stud strains in Specimens B1 and B2 were slightly lower than 0.003 , except for one instrumented stud in Specimen B2, which exhibited a peak strain of 0.0045 during the $2.30 \%$ drift cycle. If shear studs with actual yield strength closer to the specified yield stress had been used, the shear studs may have yielded at lower drifts (the ratio of reported to specified yield strength exceeded 1.25 for Specimens B1 and B2).

In Specimen B3, with stud rails placed diagonally from each column corner, strains in the studs near the corner were

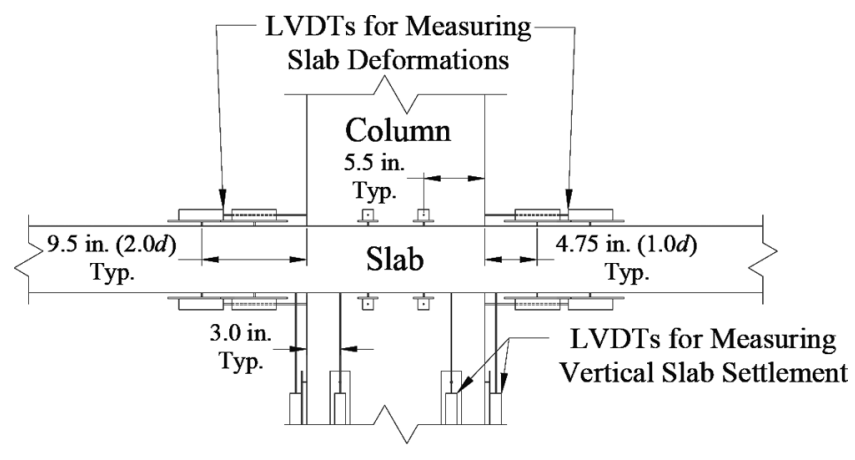

Fig. 10-Placement of linear variable differential transformers (LVDTs) at slab-column connection. (Note: 1 in. $=$ $25.4 \mathrm{~mm}$.)

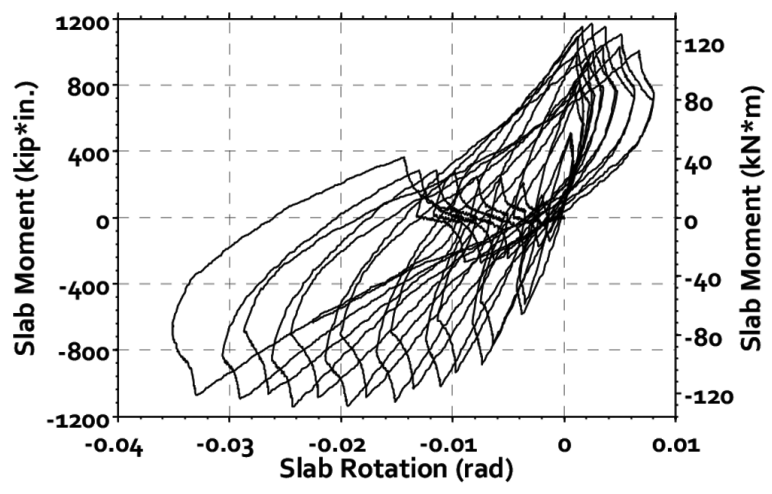

(a) Calculated at $\mathrm{d}$ from column face

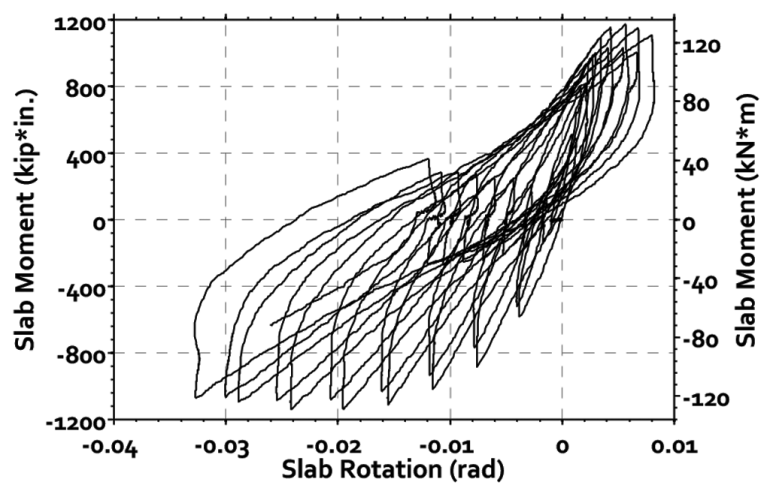

(b) Calculated at $2 \mathrm{~d}$ from column

Fig. 11-Slab moment transferred to the column about y-axis versus rotations in slab north of column in Specimen B2.

lower than those of studs on orthogonally placed rails during the drift cycles to $1.85 \%$ and higher. This behavior may have been caused by a more rapid degradation of concrete near the column corners due to higher shear stresses, which led to less engagement of the shear studs. A peak stud strain of 0.0065 was measured in one of the studs of Specimen B3 during the cycle at $2.30 \%$ drift. This substantial increase in peak stud strain compared to that in Specimens B1 and B2 was due to this particular stud being anchored by a top slab bar. Strains in the other instrumented studs were below approximately 0.0035 .

Due to the greater number of shear studs in Specimen B4, force demands on individual studs were lower after diagonal 
cracks had formed than in the other specimens, resulting in lower recorded strains. Peak strains in the first two rows of studs in Specimen B4 typically ranged from 0.001 to 0.0015 .

\section{Shear studs and concrete confinement}

It is evident from visual observations during and after testing that the slab concrete was not well confined (Fig. 7 and 9). Rather than a well-confined core of concrete between the top and bottom mats of reinforcement, large, loose pieces of concrete and crushed "gravel-like" debris were found after the tests were completed. Furthermore, the concrete in the immediate vicinity of the headed studs was also not well confined. In some instances, a cylinder of concrete around the stud shank with a diameter smaller than the stud head remained intact after testing, indicating that it was either confined by or bonded to the stud. In other cases, the stud shank was exposed after testing, indicating that no concrete was effectively confined by the shear stud.

Transfer of shear stresses within a slab-column connection ultimately relies on the ability of the concrete to resist diagonal compression. Although the headed studs in the tested specimens bridged diagonal cracks through several displacement cycles, they did not prevent significant degradation of the concrete in the connection region at large drift cycles. Once the concrete had substantially degraded, the connection lost its ability to resist shear. It is expected that concrete degradation would have been delayed and a larger drift capacity would have been observed if the headed stud reinforcement effectively confined the concrete. Conversely, had the connection been subjected to shear reversals of a magnitude closer to the upper limit in ACI 318-11 of $8 \sqrt{ } f_{c}{ }_{c}^{\prime}$, psi $\left(0.67 \sqrt{ } f_{c}^{\prime}, \mathrm{MPa}\right)$, more severe (and earlier) concrete degradation would likely have occurred (the calculated combined peak shear stress did not exceed $4.4 \sqrt{ } f_{c}{ }^{\prime}$, psi $\left[0.37 \sqrt{ } f_{c}{ }^{\prime}, \mathrm{MPa}\right]$ for loading in either the $\mathrm{x}$ - or $\mathrm{y}$-direction in any of the test specimens).

As the test results show, concrete degradation can be significant during large displacement reversals in connections that are reinforced with shear studs and subjected to gravity shear ratios of approximately $50 \%$. For such connections, limiting lateral displacements to $2.0 \%$ resultant drift when accounting for simultaneous biaxial lateral displacements seems adequate. In connections subjected to lower levels of shear stress and lateral displacements, it is possible that concrete degradation would be more limited in the connection and therefore have a less significant impact on drift capacity.

\section{Minimum shear stud reinforcement and maximum peripheral shear stud spacing}

Specimen B2 was reinforced with shear reinforcement such that $v_{s}=3.6 \checkmark f_{c}^{\prime}$, psi $\left(0.30 \sqrt{ } f_{c}^{\prime}, \mathrm{MPa}\right)$, calculated using the cylinder concrete strength measured the day before testing. This is approximately equal to the minimum shear reinforcement amount required in Section 21.13.6 of ACI 318-11 when neither a drift nor a combined shear-stress check is performed. As discussed previously, this specimen first exhibited signs of punching shear failure during the cycle to $1.85 \%$ drift $(2.60 \%$ resultant drift), but gravity load capacity was maintained throughout the cycle at this drift level. This suggests this minimum reinforcement is adequate for connections subjected to a gravity shear ratio of up to $50 \%$ and resultant drifts from biaxial displacements of $2.0 \%$. For larger drifts, as indicated by the behavior of Specimen B2, significant shear-related damage and loss of gravity load capacity may occur. The behavior of Specimens B3 and B4 indicate that a more stringent spacing requirement for shear studs within the first three peripheral lines, and possibly a larger amount of shear stud reinforcement, would further increase the drift capacity of connections subjected to gravity shear ratios approximately equal to $50 \%$.

ACI 318-11 provisions require that the maximum spacing between studs in the first peripheral line not exceed $2 d$. Specimens B1, B2, and B3, which were able to maintain their gravity load capacity through at least the full cycle at $1.85 \%$ drift $(2.60 \%$ resultant drift), had maximum stud spacing of approximately $1.5 \mathrm{~d}$ in the first peripheral line and $2.0 \mathrm{~d}$, $2.9 d$, and $2.0 d$ in the third peripheral line, respectively. The maximum stud spacing in the third peripheral line of Specimen B4, on the other hand, was $1.4 d$. The entire loading cycle to $2.75 \%$ drift (3.9\% resultant drift) was completed when testing Specimen B4, and it never lost its gravity load capacity despite the slab dropping more than 2 in. $(50 \mathrm{~mm})$ below its initial elevation. Although the amount of shear stud reinforcement provided in Specimen B4 was substantially greater than that provided in the other three specimens, the closer stud spacing within the first three peripheral lines (which helped delay concrete degradation) is believed to be responsible for the increased drift capacity exhibited by this specimen rather than the large theoretical shear capacity. Thus, it seems sensible, based on the limited data, to limit stud spacing within the first three peripheral lines to $1.5 d$ for connections with gravity shear ratios approximately equal to $50 \%$ and resultant biaxial drifts greater than $2 \%$.

\section{Drift capacity and gravity-shear ratio}

Figure 12 shows a plot of drift capacity versus gravity shear ratio for the specimens tested in this investigation and slabcolumn connection tests reported in the literature (Broms 2007; Cheng 2009; Dilger and Cao 1991; Dilger and Brown 1994; Durrani et al. 1995; Farhey et al. 1993; Hawkins et al. 1974; Islam and Park 1976; Kang et al. 2013; Megally 1998; Megally and Ghali 2000; Morrison and Sozen 1981; Pan and Moehle 1989; Robertson 1990; Rha et al. 2014; Robertson et al. 2002; Robertson and Johnson 2006; Symonds et al. 1976; Tian et al. 2008; Wey and Durrani 1992; Zee and Moehle 1984). For Specimens B1 through B4, drift capacity was defined as the maximum resultant drift of the last loading cycle completed prior to loss of gravity load capacity and/ or severe concrete degradation that required frequent reapplication of gravity load. The gravity shear ratio used in Fig. 12 was calculated using the applied gravity load. Drift capacities from previous studies are those reported by each investigator and not necessarily based on the same criterion, as the level of detail of reported results did not allow for the use of a uniform definition of drift capacity. The plotted values typically represent the uniaxial drift recorded prior to either a $20 \%$ loss of lateral strength or a sudden connection 
failure. Drift capacity versus gravity shear ratio interaction for slab-column connections without shear reinforcement in ACI 318-11 and Hueste and Wight (1999) are also plotted in Fig. 12.

The ultimate drift capacity of the specimens tested in this investigation, while greater than that of specimens without shear reinforcement, was substantially lower than the drift capacity exhibited by other shear-stud-reinforced specimens. This lower drift capacity is likely the result of: 1) the relatively low, but realistic, flexural reinforcement ratio of $0.7 \%$ used in the column strip, and 2) the application of biaxial, rather than uniaxial, displacements. It is also likely that the use of prestressing strands to apply gravity load - a more realistic method for applying gravity loads than jacking of the column - played a role in the different behavior observed in the test specimens reported herein compared to previous test results.

\section{CONCLUSIONS}

The following conclusions were drawn based on the results from tests of four large-scale slab-column connection specimens reinforced with shear studs and subjected to combined gravity load and biaxial lateral displacements. Because of the limited scope of the test series, caution should be exercised when evaluating implications on the design of connections significantly different from the test specimens, including prestressed (for example, post-tensioned) slabs.

1. The four specimens tested in this investigation exhibited lower drift capacities than previously reported for shear-stud-reinforced slab-column connections tested under gravity shear ratios of approximately $50 \%$. Observed drift capacities in each perpendicular direction were $1.85 \%$ (2.60\% resultant drift) for Specimens B1, B2, and B3 and $2.30 \%$ (3.20\% resultant drift) for Specimen B4. Loss of gravity-load-carrying capacity occurred early in the cycle to $2.30 \%$ drift (3.20\% resultant drift) in Specimens B1 and B2. Specimens B3 and B4 continued to carry imposed gravity loads until the tests were terminated during and at the end of the cycle to $2.75 \%$ drift (3.90\% resultant drift), respectively.

2. Shear studs did not provide adequate confinement of the concrete under inelastic deformation reversals. Severe concrete degradation developed in Specimens B1, B2 and $\mathrm{B} 3$ beginning in the cycle to $1.85 \%$ drift $(2.60 \%$ resultant drift). Concrete degradation was delayed in Specimen B4, which had a maximum stud spacing of $1.4 d$ within the first three peripheral lines. The cycle to $2.75 \% \mathrm{drift}$ (3.90\% resultant drift) was completed when testing Specimen B4 without loss of gravity load capacity.

3. Based on the behavior of Specimen B2, the minimum shear reinforcement amount required in Section 21.13.6 of ACI 318-11 when neither a drift nor a combined shearstress check is performed appears adequate for connections subjected to a gravity shear ratio of up to $50 \%$ and resultant drifts from biaxial displacements of up to $2.0 \%$.

4. It is recommended that the stud spacing within the first three peripheral lines be limited to $1.5 d$ for connections subjected to gravity shear ratios similar to those applied in this study (50\%) and resultant drifts, from biaxial displace-

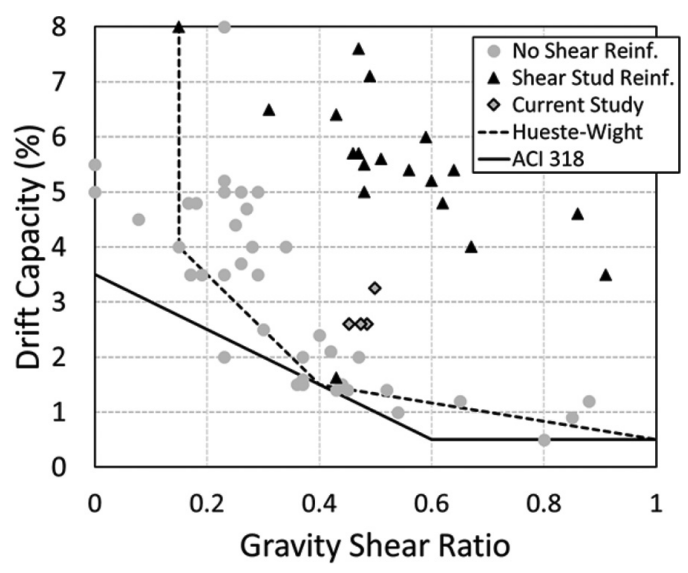

Fig. 12-Drift capacity versus gravity shear ratio for slabcolumn connection specimens.

ments, greater than $2.0 \%$, as supported by the behavior exhibited by Specimen B4.

5. Studs located so the head was bearing on the top layer of slab flexural reinforcement exhibited much better anchorage than studs anchored only in concrete. Double curvature bending of the base rails was observed near such studs after failure because the well-anchored studs did not drop downward with the surrounding slab.

6. Yielding of a shear stud, when observed, was associated with extensive punching-related damage. Although Specimens B1 and B2 developed punching with none of the instrumented studs exhibiting inelastic strains, Specimens B3 and B4 exhibited extensive punching-related damage coincident with detection of yielding in a shear stud.

\section{AUTHOR BIOS}

Eric M. Matzke is a Structural Engineer at Hammel, Green, and Abrahamson, Minneapolis, $M N$.

ACI member Rémy D. Lequesne is an Assistant Professor of Civil, Environmental and Architectural Engineering at the University of Kansas, Lawrence, KS. He is Secretary of Joint ACI-ASCE Committee 408, Bond and Development of Steel Reinforcement, and a member of ACI Subcommittee 318-J, Joints and Connections (Structural Concrete Building Code), and Joint ACI-ASCE Committee 352, Joints and Connections in Monolithic Concrete Structures. His research interests include the behavior of reinforced concrete members and earthquake-resistant design.

Gustavo J. Parra-Montesinos, FACI, is the C.K. Wang Professor of Structural Engineering at the University of Wisconsin-Madison, Madison, WI. He is Chair of ACI Subcommittee 318-J, Joints and Connections (Structural Concrete Building Code), and a member of ACI Committee 318, Structural Concrete Building Code. He is also member of Joint ACI-ASCE Committee 335, Composite and Hybrid Structures, and 352, Joints and Connections in Monolithic Concrete Structures. His research interests include the behavior and design of reinforced concrete, fiber-reinforced concrete, and hybrid steel-concrete structures.

Carol K. Shield, FACI, is a Professor of civil engineering at the University of Minnesota, Minneapolis, MN. She is Chair of ACI Committee 440, Fiber-Reinforced Polymer Reinforcement. Her research interests include methods of seismic simulation, behavior of prestressed concrete members, and fiber-reinforced polymers.

\section{ACKNOWLEDGMENTS}

This research was supported by the National Science Foundation as part of the Network for Earthquake Engineering Simulation (NEES) Program (Grant No. 0936519), the Charles Pankow Foundation, and the Concrete Research Council of the American Concrete Institute. Erico International Corporation donated bar reinforcement and mechanical splices used in 
construction of the specimens. The opinions presented in this report are those of the authors and do not necessarily express the views of the sponsors.

\section{REFERENCES}

ACI Committee 318, 2011, "Building Code Requirements for Structural Concrete (ACI 318-11) and Commentary," American Concrete Institute, Farmington Hills, MI, 503 pp.

ASTM A615/A615M-09, 2009, "Standard Specification for Deformed and Plain Carbon-Steel Bars for Concrete Reinforcement," ASTM International, West Conshohocken, PA, 6 pp.

Broms, C. E., 2007, "Flat Plates in Seismic Areas: Comparison of Shear Reinforcement Systems," ACI Structural Journal, V. 104, No. 6, Nov.-Dec., pp. 712-721.

Cheng, M.-Y., 2009, "Punching Shear Strength and Deformation Capacity of Fiber Reinforced Concrete Slab-Column Connections under Earthquake-Type Loading," PhD dissertation, University of Michigan, Ann Arbor, MI, 334 pp.

Cheng, M.-Y.; Parra-Montesinos, G. J.; and Shield, C. K., 2010, "Shear Strength and Drift Capacity of Fiber-Reinforced Concrete Slab-Column Connections Subjected to Biaxial Displacements," Journal of Structural Engineering, ASCE, V. 136, No. 9, pp. 1078-1088. doi: 10.1061/(ASCE) ST.1943-541X.0000213

Comité Européen de Normalisation, 2004, "Eurocode 2: Design of Concrete Structures — Part 1-1: General Rules and Rules for Buildings (EN 1992-1-1:2004)," Brussels, Belgium, 225 pp.

Dilger, W. H., and Brown, S. J., 1994, "Earthquake Resistance of SlabColumn Connections," Proceedings of Canadian Society of Civil Engineering Conference, Winnipeg, MB, Canada, pp. 388-397.

Dilger, W. H., and Cao, H., 1991, "Behavior of Slab-Column Connections Under Reversed Cyclic Loading," Proceedings of the 2nd International Conference of High-Rise Buildings, China.

Durrani, A. J.; Du, Y.; and Luo, Y. H., 1995, "Seismic Resistance of Nonductile Slab-Column Connections in Existing Flat-Slab Buildings," ACI Structural Journal, V. 92, No. 4, July-Aug., pp. 476-487.

Farhey, D. N.; Adin, M. A.; and Yankelevsky, D. Z., 1993, "RC Flat Slab-Column Subassemblages Under Lateral Loading," Journal of the Structural Division, ASCE, V. 119, No. 6, pp. 1903-1916. doi: 10.1061/ (ASCE)0733-9445(1993)119:6(1903)

Hawkins, N. M.; Mitchell, D.; and Sheu, M. S., 1974, "Cyclic Behavior of Six Reinforced Concrete Slab-Column Specimens Transferring Moment and Shear," Progress Report, University of Washington, Seattle, WA.

Hueste, M. B., and Wight, J. K., 1999, "Nonlinear Punching Shear Failure Model for Interior Slab-Column Connections," Journal of Structural Engineering, ASCE, V. 125, No. 9, pp. 997-1008. doi: 10.1061/ (ASCE)0733-9445(1999)125:9(997)

Islam, S., and Park, R., 1976, "Tests on Slab-Column Connections with Shear and Unbalanced Flexure," Journal of the Structural Division, ASCE, V. 102, No. 3, pp. 549-568.
Kang, S.-M.; Park, H.-G.; and Kim, Y.-N., 2013, "Lattice-Reinforced Slab-Column Connections under Cyclic Lateral Loading," ACI Structural Journal, V. 110, No. 6, Nov.-Dec., pp. 929-940.

Matzke, E.; Lequesne, R. D.; Shield, C. K.; and Parra-Montesinos, G. J., 2013, Drift Capacity of Slab-Column Connections Reinforced with Headed Shear Studs and Subjected to Combined Gravity Load and Biaxial Displacements, 256 pp.

Megally, S. H., 1998, "Punching Shear Resistance of Concrete Slabs to Gravity and Earthquake Forces," PhD dissertation, Department of Civil Engineering, University of Calgary, AB, Canada, 468 pp.

Megally, S. H., and Ghali, A., 2000, "Seismic Behavior of Edge ColumnSlab Connections with Stud Shear Reinforcement," ACI Structural Journal, V. 97, No. 1, Jan.-Feb., pp. 53-60.

Morrison, D. G., and Sozen, M. A., 1981, "Response of Reinforced Concrete Plate-Column Connections to Dynamic and Static Horizontal Loads," PFR-78-16318, University of Illinois at Urbana-Champaign, Urbana, IL, 272 pp.

Pan, A., and Moehle, J. P., 1989, "Lateral Displacement Ductility of Reinforced Concrete Flat Plates," ACI Structural Journal, V. 86, No. 3, May-June, pp. 250-258.

Rha, C.; Kang, T. H.-K.; Sin, M.; and Yoon, J. B., 2014, "Gravity and Lateral Load-Carrying Capacities of Reinforced Concrete Flat Plate Systems," ACI Structural Journal, V. 111, No. 4, July-Aug., pp. 753-764.

Robertson, I. N., 1990, "Seismic Response of Connections in Indeterminate Flat-Slab Subassemblies," PhD thesis, Department of Civil Engineering, Rice University, Houston, TX, 284 pp.

Robertson, I. N., and Johnson, G., 2006, "Cyclic Lateral Loading of Nonductile Slab-Column Connections," ACI Structural Journal, V. 103, No. 3, May-June, pp. 356-364.

Robertson, I. N.; Tadashi, K.; Lee, J.; and Enomoto, B., 2002, "Cyclic Testing of Slab-Column Connections with Shear Reinforcement," $A C I$ Structural Journal, V. 99, No. 5, Sept.-Oct., pp. 605-613.

Symonds, D. W.; Mitchell, D.; and Hawkins, N. M., 1976, "Slab-Column Connections Subjected to High Intensity Shears and Transferring Reversed Moments," Report No. SM 76-2, Division of Structures and Mechanics, Department of Civil Engineering, University of Washington, Seattle, WA.

Tian, Y.; Jirsa, J. O.; Bayrak, O., Widianto; and Argudo, J. F., 2008, "Behavior of Slab-Column Connections of Existing Flat-Plate Structures," ACI Structural Journal, V. 105, No. 5, Sept.-Oct. pp. 561-569.

Wey, E. H., and Durrani, A. J., 1992, "Seismic Response of Interior SlabColumn Connections with Shear Capitals," ACI Structural Journal, V. 89, No. 6, Nov.-Dec., pp. 682-691.

Zee, H. L., and Moehle, J. P., 1984, "Behavior of Interior and Exterior Flat Plate Connections Subjected to Inelastic Load Reversals," Report No. $U C B / E E R C-84 / 07$, Earthquake Engineering Research Center, University of California, Berkley, Berkley, CA, 130 pp. 